\title{
Shock Compression of Ilmenite
}

\author{
David A. King and Thomas J. Ahrens \\ Seismological Laboratory, California Institute of T--hnology. Pasndena. California 91125
}

\begin{abstract}
Single- and reflected-shock compression measurements on single-crystal ilmenite $(\mathrm{FeTiO})$ to pressures of 635 and $930 \mathrm{kbar}$, respectively, demonstrate anomalously large compressions above $\sim 320 \mathrm{kbar}$ and imply the onset of one or more major phase changes at this pressure level which continue to occur to at least $\sim 600 \mathrm{kbar}$. The phase change onset pressure is considerably above the calculated upper bound of $193 \mathrm{kbar}$ for the stability of ilmenite with respect to breakdown into wustite and rutile. Over the 300- to 600-kbar range, samples shocked along the $c$ axis are consistently more compressible than those shocked along the perpendicular direction; at a given density the Hugoniot curves differ by $40 \mathrm{kbar}$. The observed density $\left(6.25 \mathrm{~g} / \mathrm{cm}^{3}\right)$ of the highest-pressure single-shock state implies that the shock-induced highpressure phase has a zero-pressure density of at least $5.4 \mathrm{~g} / \mathrm{cm}^{3}$, or a density $13 \% \mathrm{greater}$ than that of ilmenite. The reflected-shock data have a larger experimental uncertainty but indicate an even greater zero-pressure density for the high-pressure phase. The large density increase inferred restricts the possible nature of the high-pressure phase. These data are consistent with the 1300 -kbar datum reported by Simakov et al. (1974) and with the disproportionment of ilmenite into mixed oxides in the rock salt (FeO) and fluorite $\left(\mathrm{TiO}_{2}\right)$ phases as observed (Liu, 1975) in static recovery experiments.
\end{abstract}

\section{INTRODUCTION}

The effect of shock compression on ilmenite is of importance on the moon because of the apparent ease with which characteristic deformation elements are induced by meteorite impact and because this mineral is the isotype of the highpressure phase of the pyroxene component of the earth's mantle. Although ilmenite is only a minor rock-forming mineral, making up some $10 \%$ of certain mare basalts, characteristic shock-induced structural damage results from shocks with amplitudes as low as $\sim 75 \mathrm{kbar}$ [Sclar et al., 1973; Minkin and Chao, 1971]. Furthermore, the observation of pseudobrookite and rutile in the heavily shocked Ries crater glass [El Goresy et $a l ., 1968]$ indicates that ilmenite may break down into oxides as the result of shock-induced high-temperature oxidation.

In addition to simple breakdown into oxides a series of structures into which pyroxene and other $\mathrm{A}^{+2} \mathrm{~B}^{+4} \mathrm{O}_{\mathrm{a}}$ compounds may transform under shock, static high pressure, or lower mantle conditions have been investigated by Ringwood [1970] and Reid and Ringwood [1969, 1975]. The research which this group has carried out on $\mathrm{Ge}^{+4}$ and $\mathrm{Ti}^{+4}$ analog compounds suggests that the following possible polymorphic sequence occurs with increasing pressure: pyroxene-garnet(majorite)-ilmenite-perovskite. The high-pressure Hugoniot data for pyroxenes and garnet [McQueen et al., 1967b; Ahrens and Gaffney, 1971; Graham and Ahrens, 1973] and their interpretation both in terms of these polymorphs and in some cases in terms of the possible transformation of $\mathrm{Fe}^{+2}$ from the high-spin to low-spin electronic configuration have recently been reveiwed by Davies and Gaffney [1973]. Although the pyroxene data suggest that this mineral undergoes successive transformation through the above series, the association of density-pressure states along the Hugoniot with specific polymorphic forms, other than pyroxene itself, is still unclear.

Liu et al. [1974] have reported high-pressure $\mathrm{X}$ ray diffraction data for magnesian ilmenite $\left(\mathrm{Il}_{48} \mathrm{Gk}_{41} \mathrm{Hm}_{19}\right)$ to $275 \mathrm{kbar}$ at room temperature, a finding which supplements the earlier approximate bulk modulus measured for ilmenite (1.8 Mbar) by Bridgman [in Birch, 1966]. Recently, Simakov et al. [1974] have also reported several Hugoniot data extending to 1.3 Mbar for an ilmenite with an initial density of $4.75 \mathrm{~g} / \mathrm{cm}^{3}$, and

Copyright $\odot 1976$ by the American Geophysical Union.
Liu [1975] has carried out two diamond-anvil laser recovery experiments (from $\sim 140$ and $\sim 250 \mathrm{kbar}$ ) on a magnesian ilmenite having a composition similar to that of the samples previously studied.

The present study of the shock compression of ilmenite is motivated both by a need to provide a Hugoniot curve for interpreting the impact effects on this mineral and by a need to provide new data on the possible phase changes of high-pressure forms of pyroxene.

\section{EXPERIMENTS}

A series of $\sim 4-\mathrm{mm}$-thick, $\sim 15-\mathrm{mm}$-diameter samples were cut, both parallel and perpendicular to the $c$ axis, from a partially twinned single crystal of ilmenite (from Blafjell, Norway) obtained from Inge Bryhni (curator of the MineralogicalGeological Museum in Oslo). Although microscopic examination revealed several percent of exsolved hematite, microprobe analysis (by A. A. Chodos of the California Institute of Technology) of the ilmenite phase gave a stoichiometry corresponding to $\left(\mathrm{Fe}_{0.98}, \mathrm{Mn}_{0.07} \mathrm{Ti}_{\mathbf{0 . 9 4}}\right) \mathrm{O}_{3}$. Macroscopic specimen densities varied from 4.73 to $4.80 \mathrm{~g} / \mathrm{cm}^{3}$ (Table 1), values which are close to the density of ilmenite $\left(4.79 \mathrm{~g} / \mathrm{cm}^{3}\right)$.

The Hugoniot data were obtained by projectile impact with 2.5-mm-thick plates of tungsten, 2024 aluminum, and tantalum, and the resultant shock and free surface velocity were recorded by a streak camera [Ahrens et al., 1971]. Standard Hugoniots for the driver and flyer plates are taken from work of McQueen et al. [1970]. In most cases the velocity of a single shock through the specimen and the corresponding ilmenite free surface velocity were determined. However, in later experiments, in an attempt to reach higher pressures, the initial shock wave was reflected back through the sample by a flat tungsten plate ( $3 \mathrm{~mm}$ thick) placed against the upper specimen surface (Figures 1 and 2). In these experiments (Table 2) the shock state corresponding to the direct wave was determined as it had been before, while the reflected-shock state was computed from the shock velocity and/or the free surface velocity of the upper tungsten plate. Although the reflected-shock data show a large amount of scatter (Figure 3), the data obtained from the tungsten shock velocity and the tungsten free surface measurement are consistent. This indicates that the flyer plates used in these experiments were sufficiently thick $(3.75 \mathrm{~mm})$ 
TABLE 1. Hugoniot

\begin{tabular}{|c|c|c|c|c|}
\hline Shot & $\begin{array}{l}\text { Projectile Velocity, } \\
\mathrm{km} / \mathrm{s}\end{array}$ & $\begin{array}{l}\text { Driver and Flyer } \\
\text { Plate Material }\end{array}$ & $\begin{array}{l}\text { Initial Density, } \\
\mathbf{g} / \mathbf{c m}^{\mathbf{3}}\end{array}$ & $\begin{array}{c}\text { Shock Velocity, } \\
\mathrm{km} / \mathrm{s}\end{array}$ \\
\hline 306 & $0.919 \pm 0.015$ & 2024 aluminum & 4.749 & $6.288 \pm 0.11$ \\
\hline 307 & $1.118 \pm 0.015$ & 2024 aluminum & 4.797 & $7.527 \pm 0.08$ \\
\hline 310 & $1.307 \pm 0.016$ & polycrystalline tantalum & 4.785 & $7.90 \pm 0.10$ \\
\hline 308 & $1.727 \pm 0.019$ & polycrystalline tantalum & 4.785 & $7.734 \pm 0.06$ \\
\hline 309 & $2.310 \pm 0.026$ & polycrystalline tantalum & 4.773 & $7.643 \pm 0.06$ \\
\hline 324 & $1.274 \pm 0.015$ & polycrystalline tantalum & 4.766 & $7.296 \pm 0.04$ \\
\hline 316 & $1.557 \pm 0.019$ & polycrystalline tantalum & 4.774 & $7.239 \pm 0.03$ \\
\hline 326 & $2.024 \pm 0.020$ & polycrystalline tungsten & 4.766 & $7.295 \pm 0.04$ \\
\hline 320 & $2.160 \pm 0.030$ & polycrystalline tungsten & 4.761 & $7.323 \pm 0.04$ \\
\hline 321 & $2.46 \pm 0.040$ & polycrystalline tungsten & 4.754 & $7.462=0.010$ \\
\hline 334 & $1.922 \pm 0.015$ & polycrystalline tungsten & 4.765 & $7.105 \pm 0.037$ \\
\hline
\end{tabular}

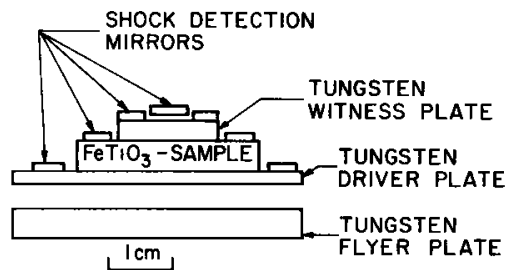

Fig. 1. Cross-sectional view of reflected-shock experiment.

that a rarefaction wave which propagated forward from the rear flyer plate surface did not attenuate the shock propagating through the sample and tungsten reflectors prior to arrival at the free surface.

\section{RESULTS}

The results given in Tables 1 and 2 and Figure 3 are striking in two respects. They indicate both very large compression above 300 kbar and a marked anisotropy of compression which remains to pressures of $565 \mathrm{kbar}$. Although the four Hugoniot data points obtained below $320 \mathrm{kbar}$ indicate a slightly less compressible behavior than was indicated by Liu et al. [1974] (for magnesian ilmenite), our datum point at 290 kbar lies close to the $X$ ray data. The large compression inferred for states obtained between 320 and $650 \mathrm{kbar}$ indicates the occurrence of one or more major phase changes. The reflected-shock data which have large experimental uncertainties may tentatively be considered to be approximately representative of the properties of the high-pressure phase (discussed below).

For the $c$ orientation, Table 1 demonstrates that the shock velocity remains nearly constant over a range corresponding to pressures of 300-600 kbar. The three data points for the orientation perpendicular to the $c$ axis in this pressure range appear to show a slight increase in shock velocity with increasing projectile velocity. This finding implies shock instability, which was not clearly observed. However, for shot 308 (final shock pressure, $417 \mathrm{kbar}$ ) both the shock arrival mirrors and the free surface velocity profiles observed with the inclined mirror indicated the presence of a precursor shock traveling about $0.2 \mathrm{~km} / \mathrm{s}$ slower than that associated with the final shock state. However, accounting for an intermediate shock state did not change our calculation of the final pressure by an amount greater than the indicated uncertainty.

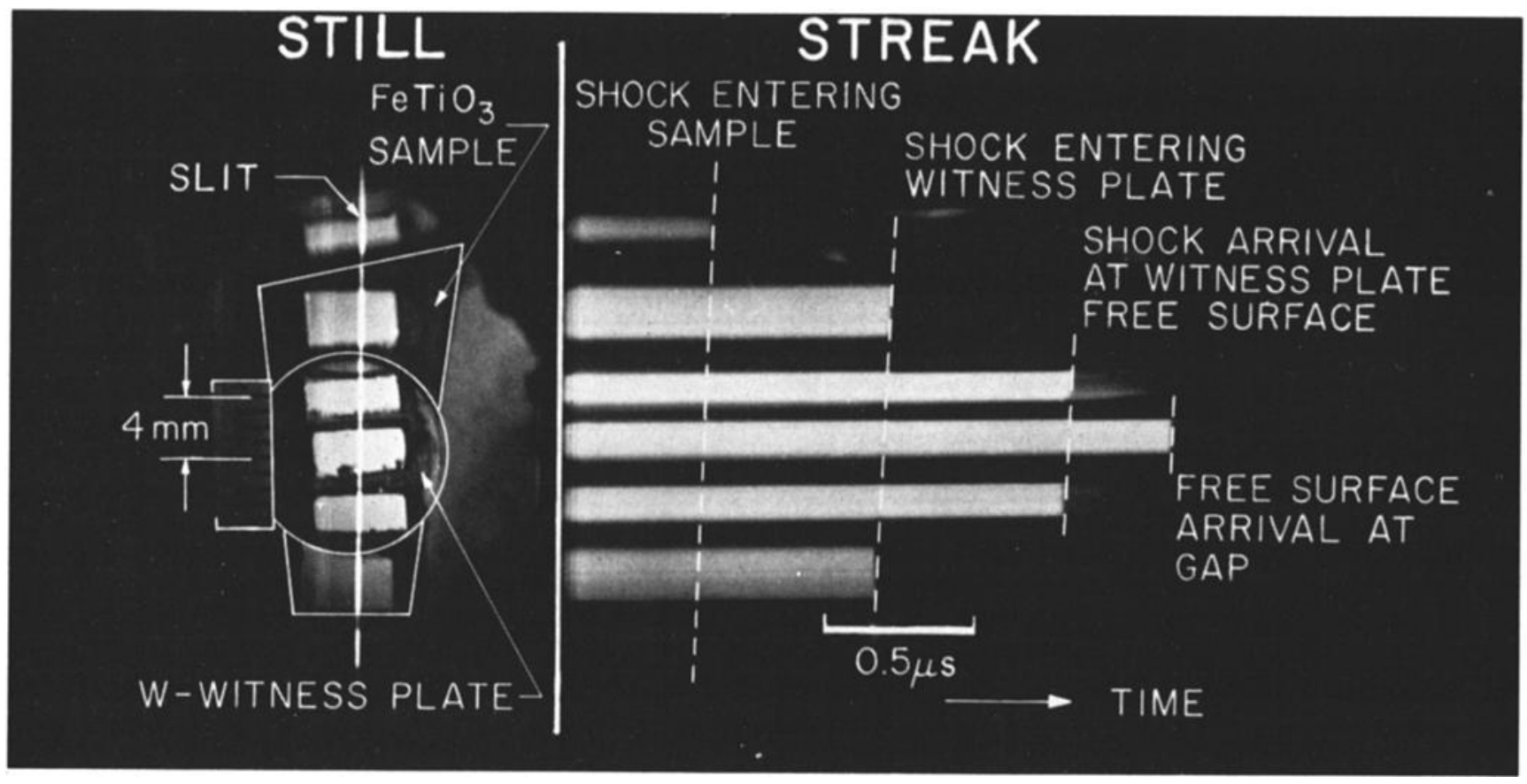

Fig. 2. Photograph of experimental assembly as seen through streak camera and resultant streak record. 
Data for Ilmenite

\begin{tabular}{|c|c|c|c|c|}
\hline $\begin{array}{c}\text { Particle Velocity, } \\
\mathrm{km} / \mathrm{s}\end{array}$ & $\begin{array}{c}\text { Shock Pressure, } \\
\text { kbar }\end{array}$ & Density, $\mathrm{g} / \mathrm{cm}^{2}$ & $\begin{array}{c}\text { Free Surface Velocity, } \\
\mathrm{km} / \mathrm{s}\end{array}$ & $\begin{array}{l}\text { Orientation of Shock } \\
\text { Direction to } c \text { Axes }\end{array}$ \\
\hline $\begin{array}{r}0.332 \pm 0.010 \\
0.390 \pm 0.010 \\
0.837 \pm 0.009 \\
1.127 \pm 0.011 \\
1.535 \pm 0.024 \\
0.834 \pm 0.010 \\
1.032 \pm 0.012 \\
1.464 \pm 0.013 \\
1.588 \pm 0.019 \\
1.786 \pm 0.028 \\
1.45 \pm 0.015\end{array}$ & $\begin{array}{l}99 \pm 3 \\
140 \pm 3 \\
316 \pm 5 \\
417 \pm 6 \\
564 \pm 7 \\
290 \pm 5 \\
357 \pm 4 \\
509 \pm 4 \\
537 \pm 6 \\
633 \pm 10 \\
473 \pm 3\end{array}$ & $\begin{array}{l}5.013 \pm 0.01 \\
5.059 \pm 0.01 \\
5.352 \pm 0.008 \\
5.601 \pm 0.009 \\
5.973 \pm 0.010 \\
5.381 \pm 0.008 \\
5.568 \pm 0.008 \\
5.963 \pm 0.009 \\
6.020 \pm 0.013 \\
6.246 \pm 0.020 \\
5.930 \pm 0.009\end{array}$ & $\begin{array}{l}0.51 \pm 0.1 \\
1.70 \pm 0.07 \\
2.32 \pm 0.12 \\
1.81 \pm 0.10 \\
3.10 \pm 0.20 \\
3.27 \pm 0.12\end{array}$ & $\begin{array}{l}\text { perpendicular } \\
\text { perpendicular } \\
\text { perpendicular } \\
\text { perpendicular } \\
\text { perpendicular } \\
\text { parallel } \\
\text { parallel } \\
\text { parallel } \\
\text { parallel } \\
\text { parallel } \\
\text { parallel }\end{array}$ \\
\hline
\end{tabular}

A very clear difference exists between the shock velocities observed in the two orientations in the presumed mixed phase region, which corresponds to a shock pressure difference of about $40 \mathrm{kbar}$. This difference in the behavior of the two orientations is also reflected in the free surface velocities $u_{f}$ in terms of particle velocity $u_{p}$ in the mixed phase region (Table 1). For pressures of $350 \mathrm{kbar}$ or greater,

$$
u_{f}=1.8 u_{p} \text { to } 1.9 u_{p}
$$

for the $c$ orientation and

$$
u_{f}=1.4 u_{p} \text { to } 1.6 u_{p}
$$

for the perpendicular to $c$ orientation approximate our data. Were compression completely reversible, $u_{f}$ should, of course, be approximately twice $u_{p}$. Relation (2) implies that some of the ilmenite which has transformed remains in the high-pressure phase (hpp) upon rarefaction for this orientation and hence has expanded to less than the original volume upon rarefaction. On the other hand, more of the material has re- verted back to the original phase in the other orientation. The free surface velocities thus tentatively suggest that transformation to a high-pressure phase and reversion back to a lowpressure phase occur preferentially for shocks along the $c$ axis. Another interpretation of these results might be proffered on the assumption that the stresses are, contrary to the usual assumption, far from being nearly hydrostatic. (Only the shock stress perpendicular to the shock front and not, in fact, the hydrostatic pressure can be derived from these experiments.) Hydrostaticity appears likely, however, for pressures much above the Hugoniot elastic limit, which for a mechanically weak crystal such as $\mathrm{FeTiO}_{3}$ may be only a few kilobars. We note that in the case of sodium chloride, which is certainly a very weak crystal mechanically, the Hugoniot data [Fritz et $a l ., 1971]$ for the single crystal in dicate that the transformation from the $\mathrm{NaCl}$-type to the $\mathrm{CsCl}$-type structure occurs more readily for compression along the (111) direction than along the (100) directic $n$. In this case the differences in the Hugoniot, as measured by shocks propagating along different directions,

\begin{tabular}{|c|c|c|c|c|c|c|}
\hline Shot* & $\begin{array}{c}\text { Projectile } \\
\text { Velocity, } \\
\mathrm{km} / \mathrm{s}\end{array}$ & $\begin{array}{c}\text { Initial } \\
\text { Density, } \\
\text { g/cm }\end{array}$ & $\begin{array}{c}\text { Shock } \\
\text { Velocity, } \\
\mathrm{km} / \mathrm{s}\end{array}$ & $\begin{array}{c}\text { Particle } \\
\text { Velocity, } \\
\text { km/s }\end{array}$ & $\begin{array}{l}\text { Shock } \\
\text { Pressure, } \\
\text { kbar }\end{array}$ & $\begin{array}{l}\text { Density, } \\
\mathrm{g} / \mathrm{cm}^{\mathrm{s}}\end{array}$ \\
\hline $\begin{array}{l}347 \\
349 \\
328 \\
348\end{array}$ & $\begin{array}{r}2.026 \pm 0.02 \\
2.00 \pm 0.03 \\
2.362 \pm 0.02 \\
2.013 \pm 0.03\end{array}$ & $\begin{array}{l}4.746 \\
4.754 \\
4.733 \\
4.772\end{array}$ & $\begin{array}{l}7.309 \pm 0.05 \\
7.374 \pm 0.27 \\
7.250 \pm 0.10 \\
7.247 \pm 0.03\end{array}$ & $\begin{array}{l}1.465 \pm 0.015 \\
1.46 \pm 0.03 \\
1.721 \pm 0.018 \\
1.457 \pm 0.03\end{array}$ & $\begin{array}{l}508 \pm 7 \\
505 \pm 15 \\
590 \pm 6 \\
504 \pm 13\end{array}$ & $\begin{array}{l}5.936 \pm 0.014 \\
5.928 \pm 0.030 \\
6.206 \pm 0.016 \\
5.973 \pm 0.02\end{array}$ \\
\hline
\end{tabular}

TABLE 2a. Shock Data for Ilmenite in the First-Shock State

* Shock direction was parallel to $c$ axis; flyer plate was $3.75 \mathrm{~mm}$ thick.

TABLE $2 b$. Ilmenite Reflected-Shock State From Tungsten Shock Velocity

\begin{tabular}{lccccc}
\hline Shot* & $\begin{array}{c}\text { Tungsten Shock } \\
\text { Velocity, km/s }\end{array}$ & $\begin{array}{c}\text { Particle } \\
\text { Velocity, km/s } / \mathrm{s}\end{array}$ & $\begin{array}{c}\text { Shock } \\
\text { Pressure, kbar }\end{array}$ & $\begin{array}{c}\text { Density, } \\
\mathrm{g} / \mathrm{cm}^{\mathbf{3}}\end{array}$ & $\begin{array}{c}\text { Ilmenite Shock } \\
\text { Velocity, km/s }\end{array}$ \\
\hline 347 & $4.911 \pm \mathbf{0 . 0 1 2}$ & $\mathbf{0 . 7 3 5} \pm \mathbf{0 . 2 3}$ & $\mathbf{6 9 5} \pm \mathbf{2 5}$ & $\mathbf{7 . 1 4 0} \pm \mathbf{0 . 2 6}$ & $4.32 \pm \mathbf{0 . 7}$ \\
$349 \dagger$ & $5.038 \pm \mathbf{0 . 1 1}$ & $\mathbf{0 . 8 3 1} \pm \mathbf{0 . 8 0}$ & $\mathbf{8 0 7} \pm \mathbf{9 0}$ & $\mathbf{6 . 4 3 1} \pm \mathbf{0 . 3 3}$ & $\mathbf{8 . 1} \pm \mathbf{2 . 7}$ \\
$\mathbf{3 2 8}$ & $\mathbf{5 . 1 8} \pm \mathbf{0 . 0 2 0}$ & $\mathbf{0 . 9 3 5} \pm \mathbf{0 . 0 2 4}$ & $\mathbf{9 3 0} \pm \mathbf{3 0}$ & $\mathbf{6 . 9 9 7} \pm \mathbf{0 . 1 4}$ & $\mathbf{6 . 9 6 \pm 0 . 8}$ \\
\hline
\end{tabular}

* Shock direction was parallel to $c$ axis; flyer plate was $3.75 \mathrm{~mm}$ thick.

† Less certain data.

\begin{tabular}{|c|c|c|c|c|c|}
\hline Shot* & $\begin{array}{c}\text { Tungsten } \\
\text { Free Surface } \\
\text { Velocity, km/s }\end{array}$ & $\begin{array}{c}\text { Particle } \\
\text { Velocity, km/s }\end{array}$ & $\begin{array}{c}\text { Shock } \\
\text { Pressure, kbar }\end{array}$ & $\begin{array}{l}\text { Density, } \\
\mathrm{g} / \mathrm{cm}^{3}\end{array}$ & $\begin{array}{l}\text { Ilmenite Shock } \\
\text { Velocity, } \mathrm{km} / \mathrm{s}\end{array}$ \\
\hline $\begin{array}{l}347 \\
349 \\
348\end{array}$ & $\begin{array}{l}1.424 \pm 0.038 \\
1.476 \pm 0.040 \\
1.489 \pm 0.04\end{array}$ & $\begin{array}{l}0.712 \pm 0.19 \\
0.738 \pm 0.20 \\
0.745 \pm 0.2\end{array}$ & $\begin{array}{l}670 \pm 20 \\
699 \pm 22 \\
711 \pm 22\end{array}$ & $\begin{array}{l}7.468 \pm 0.26 \\
7.042 \pm 0.19 \\
6.995 \pm 0.25\end{array}$ & $\begin{array}{l}3.62 \pm 0.6 \\
4.56 \pm 0.7 \\
3.41 \pm 0.6\end{array}$ \\
\hline
\end{tabular}

TABLE 2c. Ilmenite Reflected-Shock State From Tungsten Free Surface Velocity

- Shock direction was parallel to $c$ axis; flyer plate was $3.75 \mathrm{~mm}$ thick. 


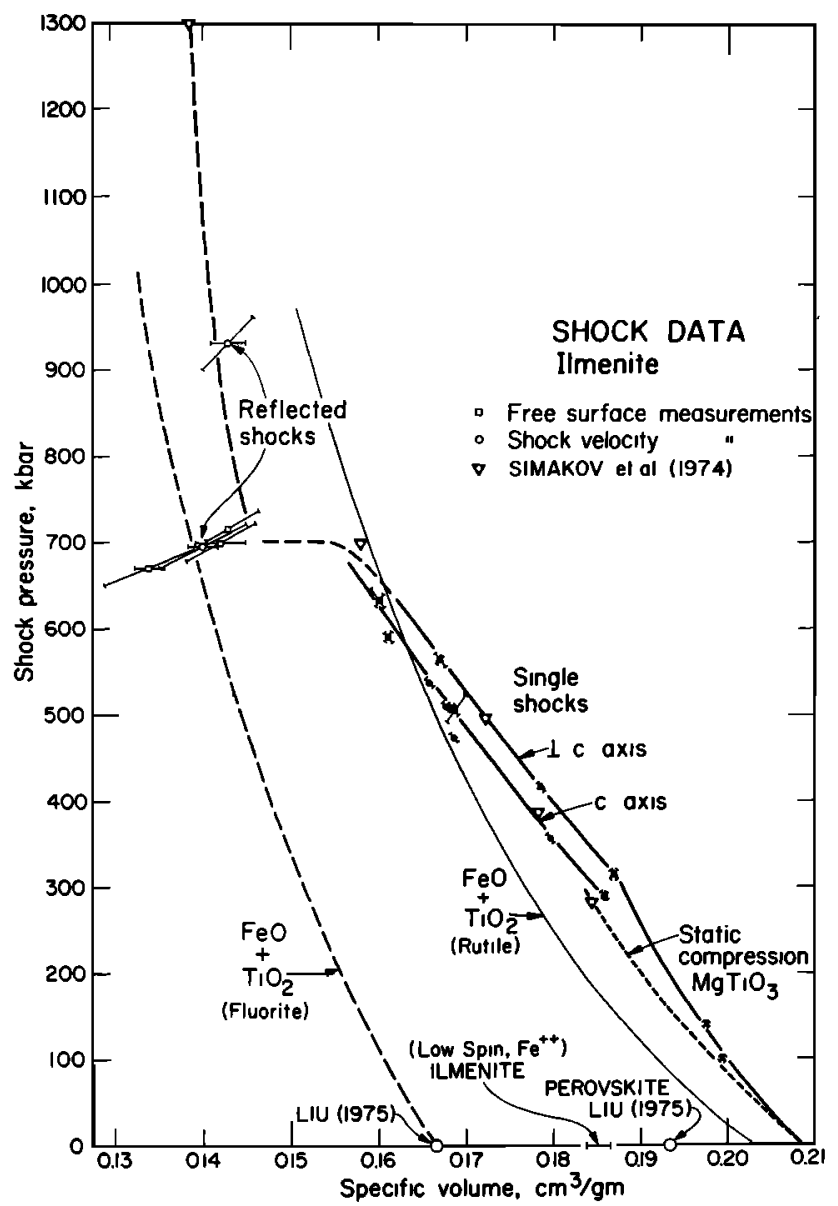

Fig. 3. Shock wave data for single-crystal ilmenite. Results of Simakov et al. [1974] are also plotted. The static compression data for magnesian ilmenite (specific volume, $0.22396 \mathrm{~cm}^{3} / \mathrm{g}$ ) of Liu et al. [1974] and the mixed oxide curve calculated by Liu [1975] have been scaled to the zero-pressure specific volume of ilmenite. Reflectedshock data obtained by using the tungsten reflector plate shock velocity and the tungsten reflector plate free surface velocity are plotted separately.

occur only in the transformation interval-in the so-called mixed phase regime.

The data for magnesian ilmenite [Liu et al., 1974] demonstrate that under presumed hydrostatic conditions this mineral is nearly twice as compressible along the $c$ axis as it is along the $a$ axis. Although this result superficially looks like ours, it does not imply that large stress differences are supportable under shock conditions. Moreover, no phase changes are reported in the $\mathrm{X}$ ray patterns to $275 \mathrm{kbar}$.

In an attempt to determine the pressure-density data for a presumed high-pressure phase above the mixed phase region, which apparently extends to at least $600 \mathrm{kbar}$, the reflection method was employed. This technique greatly increases the experimental uncertainty, primarily because the tungsten $\mathrm{Hu}$ goniot [McQueen et al., 1970] provides large pressure changes for slight changes in tungsten shock or free surface velocity. This uncertainty is then magnified by the subtraction of the first-shock pressure from the reflected-shock pressure, as is done in calculating the final density. Finally, we note that an overestimate of the initial-shock pressure in the ilmenite could occur if a precursor shock event went undetected. This could give rise to a serious overestimate of the compression arising from the reflected shock. We do not believe that this is the case, although the data are not complete enough to derive an equation of state for the higher-pressure phase.

\section{Discussion}

Both the observation that the shock velocity remains nearly constant over a wide pressure interval and the observation that the volumes above $300 \mathrm{kbar}$ are less than the high-pressure $\mathrm{X}$ ray results for magnesian ilmenite imply that above a pressure of 290-415 kbar, one or more shock-induced phase changes take place. These phase changes may go to completion in the $\sim 630$ - to $\sim 700$-kbar range of the reflected-shock Hugoniot. Because of the lack of sufficient data to calculate the Gruneisen parameter a formal shock-temperature calculation cannot be meaningfully carried out, even for the low-pressure ilmenite phase. However, some upper pressure bound on the stability of ilmenite can be obtained by calculating the phase line for the following reaction:

$$
\mathrm{FeTiO}_{3} \text { (ilmenite) } \rightarrow \mathrm{TiO}_{2} \text { (rutile) }+\mathrm{FeO} \text { (wustite) }
$$

for which thermochemical and equation of state data are available [Robie and Waldbaum, 1968]. By using the equations of state of $\mathrm{TiO}_{2}$ [Chung and Simmons, 1969], FeO [Akimoto, 1972], and $\mathrm{MgTiO}_{3}$ [Liu et al., 1974] to calculate the change in free energy at $298^{\circ} \mathrm{K}$ [Ahrens and Syono, 1967] a transition pressure of $193 \mathrm{kbar}$ is obtained. The slope of the phase line is $-18.1^{\circ} \mathrm{C} / \mathrm{kbar}$ (assumed to be straight and equal to $\Delta V / \Delta S$ ). A similar calculation for $\mathrm{MgTiO}_{8}$ yields a transition pressure of $301 \mathrm{kbar}$ (just above the range of the $\mathrm{X}$ ray experiments) and a slope of $-34.4^{\circ} / \mathrm{kbar}$. These pressures are believed to be the highest under which ilmenite can remain thermodynamically stable, in the sense that transition to an intervening phase (whose free energy is unknown) may occur at a lower pressure.

The observation of a major shock-induced phase change, starting at $\sim 200 \mathrm{kbar}$, in rutile [McQueen et al., 1967a; Linde and DeCarli, 1969; Al'tschuler et al., 1971] and the observations of Liu [1975] for magnesian ilmenite wherein a perovskite-structured $(\mathrm{Fe}, \mathrm{Mg}) \mathrm{TiO}_{3}$ was recovered from $\sim 140$ kbar and the assemblage ( $\mathrm{Fe}, \mathrm{Mg}) \mathrm{O}$ (halite) and $\mathrm{TiO}_{2}$ (fluorite) was recovered from $\sim 250 \mathrm{kbar}$ suggest that these phase changes may be occurring in the shock experiments on ilmenite. Earlier suggestions [Ahrens et al., 1969] that the highpressure phase of rutile has the fluorite structure are also supported by Liu's observation.

Using the $\sim 200$-kbar value for the onset of the transition

$$
\mathrm{TiO}_{2} \text { (rutile) } \rightarrow \mathrm{TiO}_{2} \text { (fluorite) }
$$

and the density of $6.00 \mathrm{~g} / \mathrm{cm}^{3}$ obtained by $\mathrm{Liu}$ for $\mathrm{TiO}_{2}$ (fluorite) implies a difference in free energy of $\sim 34.5 \mathrm{kcal} / \mathrm{mol}$ for reaction (4). When this value is in turn combined [e.g., Ahrens and Syono, 1967] with the free energies of ilmenite and wustite, the reaction

$$
\mathrm{FeTiO}_{3} \text { (ilmenite) } \rightarrow \mathrm{TiO}_{2} \text { (fluorite) }+\mathrm{FeO} \text { (halite) }
$$

is predicted to occur at $\sim 250 \mathrm{kbar}$ at room temperature.

It is very likely, however, that as in the case of silicates, reaction rates are extremely slow at temperatures below several hundred degrees and that the effective transition pressure, particularly in the shock case, is controlled by the shock temperature and is largely a thermally activated reaction process. Some bounds on the magnitude and equivalent zero-pressure density increase of the phase change indicated by the present data may be obtained by fitting the experimental points at 633 and $930 \mathrm{kbar}$ to Birch-M urnaghan equations with a trial value of bulk modulus of $1.8 \mathrm{Mbar}$ and $\partial K / \partial P=4$. Zero-pressure densities for a high-pressure phase of 4.99 and $5.25 \mathrm{~g} / \mathrm{cm}^{3}$ corresponding to increases of 4 and $9 \%$, respectively, are in- 
TABLE 3. Estimated Postshock Temperature for Ilmenite Shocked Perpendicular to (001)

\begin{tabular}{ccc}
\hline $\begin{array}{c}\text { Shock Pressure, } \\
\text { kbar }\end{array}$ & $\begin{array}{c}\text { Specific Volume, } \\
\mathrm{cm}^{\mathrm{a}} / \mathrm{g}\end{array}$ & $\begin{array}{c}\text { Postshock Temperature } \\
\text { Increase, }\end{array}{ }^{\circ} \mathrm{C}$ \\
\hline 104 & 0.200 & 1.8 \\
176 & 0.195 & 8 \\
263 & 0.190 & 29 \\
349 & 0.185 & 47 \\
\hline
\end{tabular}

ferred. Increasing the trial value of bulk modulus to a higher value will only increase these density values.

The total volume changes in the perovskite and mixed oxide products recovered by Liu were 8.0 and $20.2 \%$ by volume, respectively. The disproportionment involves a $29.2 \%$ volume change for the $\mathrm{TiO}_{2}$ rutile to fluorite phase change. Using the shock data of McQueen et al. [1967a] and Al'tshuler et al. [1971] for $\mathrm{TiO}_{2}$ plus his own zero-pressure volume for the hpp $\mathrm{TiO}_{2}$, Liu calculated the bulk modulus of the mixed oxide phase to be $K_{0}=2.48 \pm 0.25 \mathrm{Mbar}$, where it is assumed that $K_{0}^{\prime}=4-5$. As is shown in Figure 3, our reflected shock data are consistent with the 1300-kbar datum of Simakov et al. [1974] and agree with the expected densities for this mixed oxide phase. However, a separate perovskite phase cannot be discerned in the mixed phase region, possibly because this transformation is not rapid enough to go to completion before the inception of the second phase change or because this first transformation is not completed along the single-shock Hugoniot. The apparent observation of shock-induced disproportionment implies that chemical disproportionment can occur within the microsecond time scale of shock experiments.

Finally, with regard to impact effects on ilmenite we have carried out a simple waste heat calculation of the postshock temperature achieved by ilmenite shock perpendicular to the $c$ axis (Table 3 ). These values were calculated upon fitting the three data points below $315 \mathrm{kbar}$ (and the zero-pressure point) to a Birch-Murnaghan equation which yields an apparent bulk modulus $K=2.3 \mathrm{Mbar}$ with an assumed value of $(d K / d P)=4$. The temperature increases calculated are considerably below those required for melting $\left(1470^{\circ} \mathrm{C}\right)$.

Acknowledgments. This research was supported under contract NGL 05-002-105 and NSF grant GA 39042X. We appreciate the continued technical support of Harold Richeson and David Johnson. We thank Inge Bryhni, Curator of the Mineralogical-Geological Museum in Oslo, for the gift of the specimen material; A. A. Chodos for his microprobe analysis; and Rex V. Gibbons for assistance in examining our samples. We thank A. Reid, A. E. Ringwood, and L. Liu for sending us preprints of their papers. The comments of two anonymois reviewers were most helpful. Contribution 2552 of the Division of Geological and Planetary Sciences, California Institute of Technology.

\section{REFERENCES}

Ahrens, T. J., and E. S. Gaffney, Dynamic compression of enstatite, $J$. Geophys. Res., 76, 5504-5513, 1971.

Ahrens, T. J., and Y. Syono, Calculated mineral reactions in the earth's mantle, J. Geophys. Res., 72, 4181-4187, 1967.

Ahrens, T. J., D. L. Anderson, and A. E. Ringwood, Equations of state and crystal structures of high-pressure phases of shocked silicates and oxides, Rev. Geophys. Space Phys., 7, 667-707, 1969.
Ahrens, T. J., J. H. Lower, and P. L. Lagus, Equations of state of forsterite, J. Geophys. Res., 76, 518-528, 1971.

Akimoto, $\mathrm{S}$., The system $\mathrm{MgO}-\mathrm{FeO}_{2}-\mathrm{SiO}_{2}$ at high pressures and temperatures: Phase equilibria and elastic properties, Tectonophysics, 13. 161-188, 1972.

Al'tschuler, L. V., M. A. Podureto, G. V. Simakov, and R. F. Trunin, High density forms of fluorite and rutile, Sov. Phys. Solid State, Engl. Transl., 15, 969-971, 1971.

Birch, F., Compressibility: Elastic constants, Geol. Soc. Amer. Mem. 97. 97-173, 1966

Chung, D. H., and G. Simmons, Pressure derivatives of the elastic properties of polycrystalline quartz and rutile, Earth Planet. Sci. Lett. 6, 134-138, 1969.

Davies, G. F., and E. S. Gaffney, Identification of high pressure phases of rocks and minerals from Hugoniot data, Geophys. J. Roy. Astron. Soc., 33, 165-183, 1973.

El Goresy, A., H. Fechtig, and J. Ottemann, The opaque minerals in impactite glasses, in Shock Metamorphism of Natural Materials, edited by B. M. French and N. M. Short, pp. 531-553, Mono, Baltimore, Md., 1968.

Fritz, J. N., S. P. Marsh, W. J. Carter, and R. G. McQueen, The Hugoniot equation of state of sodium chloride in the sodium chloride structure, Nat. Bur. Stand. U. S. Spec. Publ. 326, 201-208, 1971.

Graham, E. K., and T. J. Ahrens, Shock wave compression of ironsilicate garnet, J. Geophys. Res., 78, 375-392, 1973.

Linde, R. K., and P. S. DeCarli, Polymorphic behavior of titania under dynamics loading, J. Chem. Phys., 50, 319-325, 1969.

Liu, L., High pressure phase transformations and compressions of ilmenite and rutile, 1, Experimental results, Phys. Earth Planet. Interiors, 10, 167-176, 1975.

Liu, L., W. A. Bassett, and T. Takahashi, Isothermal compressions of a spinel phase of $\mathrm{Co}_{2} \mathrm{SiO}$ and magnesian ilmenite, J. Geophys. Res. . 79, 1171-1174, 1974.

McQueen, R. G., J. C. Jamieson, and S. P. Marsh, Shock wave compression and X-ray studies of titanium dioxide, Science, 155 , 1401-1404, 1967a.

McQueen, R. G., S. P. Marsh, and J. N. Fritz, Hugoniot equation of state of twelve rocks, J. Geophys. Res., 72, 4999-5036, $1967 b$.

McQueen, R. G., S. P. Marsh, J. W. Taylor, J. N. Fritz, and W. J. Carter, The equation of state of solids from shock wave studies, in High Velocity Impact Phenomena, edited by R. Kinslow, pp. 294-419, Academic, New York, 1970.

Minkin, J. A., and E. C. T. Chao, Single crystal X-ray investigation of deformation in terrestrial and lunar ilmenite, Proc. Lunar Sci. Conf. 2nd, 1, 237-246, 1971.

Reid, A. F., and A. E. Ringwood, High-pressure scandium oxide and its place in the molar volume relationships of dense structures of $M_{2} X_{3}$ and $A B X_{3}$ type, $J$. Geophys. Res., 74, 3238-3252, 1969.

Reid, A. F., and A. E. Ringwood, High-pressure modification of $\mathrm{ScAlO}_{8}$ and some geophysical implications, J. Geophys. Res., 80. 3363, 1975.

Ringwood, A. E., Phase transformations and the constitution of the mantle, Phys. Earth Planet. Interiors, 3, 109-155, 1970.

Robie, R. A., and D. R. Waldbaum, Thermodynamic properties of minerals and related substances at $298.15^{\circ} \mathrm{K}\left(25.0^{\circ} \mathrm{C}\right)$ and one atmosphere (1.013 bars) pressure and at higher temperatures, U.S. Geol. Surv. Bull. 1259, 16-19, 1968.

Sclar, C. B., J. F. Bauer, S. J. Pickart, and H. A. Alperin, Shock effects in experimentally shocked terrestrial ilmenite, lunar ilmenite of rock fragments in $1-10 \mathrm{~mm}$ fines $(10085,19)$ and lunar rock 60015,127 , Proc. Lunar Sci. Conf. 4th, 1, 841-850, 1973.

Simakov, G. V., M. N. Pavlovskiy, N. G. Kalashnikov, and R. F. Trunin, Shock compressibility of twelve minerals, Izv. Acad. Sci. USSR Phys. Solid Earth, Engl. Transl., no. 8, 488-492, 1974.

(Received November 18, 1974; revised August 26, 1975; accepted September 5, 1975.) 